\title{
The Efficacy of Licorice Root (Glycyrrhiza Glabra) and Yarrow (Achillea Millefolium) in Preventing Radiation Dermatitis in Patients with Breast Cancer, A Randomized, Double-Blinded, Placebo-Controlled Clinical Trial
}

\author{
Mona Malekzadeh ${ }^{1}$, Saleh Sandoughdaran ${ }^{1,2}$, Fatemeh Homayi Shandiz ${ }^{3}$, Soheyla \\ Honary $^{4}$
}

${ }^{1}$ Department of Radiation Oncology, Shohada-e-Tajrish Hospital, Faculty of Medicine, Shahid Beheshti University of Medical Sciences, Tehran, Iran. ${ }^{2}$ Student Research Committee, Shahid Beheshti University of Medical Sciences, Tehran, Iran. ${ }^{3}$ Department of Radiotherapy-Oncology, Omid and Ghaem Hospitals, Mashhad University of Medical Sciences, Mashhad, Iran. ${ }^{4}$ Department of Pharmaceutics, Mazandaran University of Medical Sciences, Sari, Iran.

\begin{abstract}
Background: Radiation dermatitis is one of the most common side effects of radiotherapy for breast cancer, affecting approximately 85 percent of patients. The aim of this study is to assess the effect of Licorice root (Glycyrrhizin glabra) and Yarrow (Achillea millefolium) on preventing radiotherapy-induced dermatitis in breast cancer patients. Methods: Seventy-five patients with breast cancer who had undergone mastectomy and were planned to receive radiotherapy (RT) were enrolled in this randomized, double-blind, placebo-controlled study. The extract of Achillea millefolium and Glycyrrhizin glabra root were incorporated into a vanishing cream base. Patients were randomly divided into three groups and received Glycyrrhizin glabra cream, placebo or Achillea millefolium cream for five weeks during RT. The rate and grade of radiation dermatitis were recorded at baseline, at the end of third week and at the end of treatment using a modified Radiation Therapy Oncology Group (RTOG) grading tool. Results: At the end of the third week, the group receiving Achillea millefolium cream showed milder skin complications than other groups. At the end of treatment, rate of skin complications in groups receiving herbal drugs was lower than placebo group but it was not statistically significant. Conclusions: In conclusion, the results of this study did not present a significant difference between Glycyrrhiza glabra, Achillea millefolium and placebo on preventing radiation dermatitis.
\end{abstract}

Keywords: Breast cancer- glycyrrhiza glabra- achillea millefolium- radiation dermatitis

Asian Pac J Cancer Care, 1 (1), 9-13

\section{Introduction}

Breast cancer is the most common cancer in women and is still the most common cause of cancer-related death in women worldwide [1]. It has been shown that adjuvant Radiotherapy (RT) for breast cancer presents a benefit in terms of reducing local recurrence and deaths resulting from breast cancer [2]. Side effects of radiotherapy are inevitable; however, effort must be made to minimize them as much as possible without sacrificing the efficacy of the treatment. Reports suggest that approximately $87 \%$ of patients are expected to suffer from skin reaction [3].
Submission Date: 11/17/2016 Acceptance Date: 12/21/2016

The level of damage is related to the amount of radiation exposure. Long-term and extreme level of exposure might even result in death $[4,5]$. Most clinicians advocate the use of various topical agents, however, no standard clinical strategy has been established for preventing radiation dermatitis [6-8].

In recent years, there has been growing interest in using natural products to treat modern medical conditions. Glycyrrhiza glabra (Licorice) and Achillea millefolium (Yarrow) both are herbal plants which are known for their anti-inflammatory and anti-oxidant effects $[9,10]$. licorice have been traditionally used as a demulcent, expectorant,

Corresponding Author:

Dr. Saleh Sandoughdaran

Department of Radiation Oncology, Shohada-e-Tajrish Hospital, Faculty of Medicine, Shahid Beheshti University of Medical Sciences, Tehran, Iran.

Email: Sandoughdaran@sbmu.ac.ir 
antioxidant, and a remedy for inflammation, as well as flavoring and sweetening agents. It is also reported to have radio protective activity in several studies.[11-14] Yarrow is used popularly as an appetizer, wound healer, diuretic and is reported to be as effective as nonsteroidal alternative therapy for atopic dermatitis $[15,16]$. However, to the best of our knowledge the effect of these herbal drugs against radiotherapy induced skin dermatitis has not been investigated.

the aim of this randomized, double-blind, placebocontrolled study was to evaluate the ability of these two herbal drugs in reducing radiation dermatitis severity in patients receiving radiotherapy for breast cancer.

\section{Materials and Methods}

Part I: Preparation of vanishing creams.

The vanishing creams and plant extracts were provided by the Department of Pharmacy of Mazandaran University of Medical Sciences. The amount of the ingredients used to formulate the vanishing creams is presented in Table 1. Mixture A was heated to $70^{\circ} \mathrm{C}$. To make mixture B, borax and water were heated. Next, ammonium hydroxide and preservative were added just before emulsification at $72^{\circ} \mathrm{C}$. After adding $\mathrm{A}$ and $\mathrm{B}$, the mixture (A-B) was kept under slow agitation, until temperature dropped to $55^{\circ} \mathrm{C}$. The accurate weight of each dry extracts, which were used in mixture $\mathrm{C}$, was levigated with glycerin and mixed with propylene glycol. Finally, mixture $\mathrm{C}$ was added to mixture A-B and stirred well.

\section{Part II: Double-blind randomized clinical trial.}

This double-blind randomized clinical trial was conducted at Mashhad University of Medical Sciences, Iran, on patients with diagnosis of breast cancer, scheduled to receive adjuvant radiotherapy. Female patients between 18 and 80 years of age at the time of enrollment who had undergone mastectomy were eligible. All patients had received chemotherapy before radiotherapy. Exclusion criteria included the presence of rashes or unhealed wounds in the radiation field, planned receipt of concurrent chemotherapy with radiation and systemic lupus erythematosus or scleroderma. After obtaining the approval of the Ethics Committee of Mashhad University, the informed consent was obtained from all participants.

Patients were treated to 50 Gray in 25 fractions, over five weeks. Upon confirmation of patient eligibility, demographic data including age, body mass index (BMI), number of chemotherapy courses and the type of drug used in it, duration between last session of chemotherapy and start of radiotherapy, and amount of sweating were collected from patients. Randomization was done by simple computer randomization. All patients were divided into three equal groups, 25 patients in each group. The patients in Group 1, 2 and 3 received Glycyrrhiza glabra, placebo and Achillea millefolium, respectively, beginning with the start of radiotherapy and continuing every day during the radiotherapy period. Patients were instructed not to apply other topical skin care products during radiotherapy period.

This study was double-blind and neither the patients nor the physician who reported the skin complication were aware of the type of treatment. The treating physicians were all radiation oncologists who specialize in breast treatment. The treating physicians assessed radiation dermatitis at baseline, at the end of third week (30 Gy) and at the end of treatment (50 Gy) using a modified Radiation Therapy Oncology Group (RTOG) radiation skin-toxicity grading tool as follows:

Grade 0: without changes

Grade 1: Erythema in dermal capillaries or mild erythema, dry desquamation

Grade 2: Sensitive in contact or moist desquamation, skin edematous

Grade 3: All of the above complications and moist desquamation in all area (not exactly in skin folds), sever edematous

Grade 4: Dermal ulceration and necrosis, bleeding

All data were analyzed by SPSS software (version 13). Statistical significance for difference in quantitative variables between the three groups was tested by ANOVA and the comparison of the qualitative variables was conducted by chi-square test. A p-value less than 0.05 was considered statistically significant.

\section{Results}

Between November 2005 and April 2009, 75 patients were enrolled and randomized. 25 patients withdrew consent or did not complete the study. Therefore, the number of patients who continued to participate in the trial was 19, 14 and 17 patients in group 1, 2 and 3, respectively (Figure 1). As it is manifested in Table 2, no significant difference was noticed between groups in terms of average age, BMI, number of chemotherapy, diabetes and hypertension, degree of sweating and its severity, and hormone therapy ( $p>0.05)$.

As depicted in Table 3, number of total skin complications were similar in group 1 and 2. However, number of total skin complications was lower in patients applying Achillea millefolium cream. Although the difference was not statistically significant $(p=0.53)$.

\section{Table 1. The Formulation of Vanish Creams}

\begin{tabular}{lcc}
\hline Mixtures & Ingredients & $\%$ \\
\hline & & \\
A & Stearic Acid & 15 \\
& Cetostearyl Alcohol & 2 \\
& Mineral Oil & 2 \\
& & \\
& Borax & 1 \\
B & Ammonium Hydroxide 28\% & 1 \\
& Preservative & 0.2 \\
& Water & 71.2 \\
& & \\
C & Propylene Glycol & 4 \\
& Dry Extract & 0.6 \\
& Glycerin & 3 \\
\hline
\end{tabular}


Table 2. Baseline Characteristic of Patients

\begin{tabular}{|c|c|c|c|c|}
\hline Variable & Licorice & Placebo & Yarrow & P-Value \\
\hline Number of Patients & 19 & 14 & 17 & \\
\hline Age (years) & $47.53 \pm 9.37$ & $46.79 \pm 10.56$ & $45 \pm 11.59$ & 0.77 \\
\hline BMI $\left(\mathrm{kg} / \mathrm{m}^{2}\right)$ & $27.52 \pm 4.41$ & $6.99 \pm 5.30$ & $29.93 \pm 4.45$ & 0.18 \\
\hline $\begin{array}{l}\text { Duration from the End of } \\
\text { Chemotherapy }\end{array}$ & $25.79 \pm 12.13$ & $28.67 \pm 16.03$ & $22 \pm 7.29$ & 0.37 \\
\hline $\begin{array}{l}\text { Number of Chemotherapy } \\
\text { Sessions }\end{array}$ & $7.22 \pm 0.94$ & $6.33 \pm 1.24$ & $6.78 \pm 1.52$ & 0.20 \\
\hline Rate of Diabetes & $3(15.8 \%)$ & $3(21.4 \%)$ & $2(11.8 \%)$ & 0.77 \\
\hline Hypertension & $1(5.3 \%)$ & $1(7.1 \%)$ & $0(0 \%)$ & 0.56 \\
\hline $\begin{array}{c}\text { Rate of Sweating } \\
\text { High } \\
\text { Moderate } \\
\text { Low }\end{array}$ & $\begin{array}{c}4(21.1 \%) \\
12(63.2 \%) \\
3(15.8 \%)\end{array}$ & $\begin{array}{l}5(30.8 \%) \\
7(53.8 \%) \\
2(15.4 \%)\end{array}$ & $\begin{array}{c}6(35.3 \%) \\
11(64.7 \%) \\
0(0 \%)\end{array}$ & 0.28 \\
\hline Hormone Therapy & $13(68.4 \%)$ & $9(64.3 \%)$ & $11(64.7 \%)$ & 0.96 \\
\hline
\end{tabular}

*Data are presented as mean \pm standard deviation and number (percent).

**P value refers to ANOVA-test and $\chi 2$-test.

Table 3. Maximum Grade of Radiation Dermatitis at the End of Third Week

\begin{tabular}{lccccc}
\hline Groups & Grade 0 & Grade 1 & Grade 2 & Grade 3 & Total \\
\hline Licorice & $10(62.5 \%)$ & $5(31.3 \%)$ & $1(6.3 \%)$ & $0(0 \%)$ & $6(37.6 \%)$ \\
Placebo & $7(53.8 \%)$ & $5(38.5 \%)$ & $1(7.7 \%)$ & $0(0 \%)$ & $6(46.2 \%)$ \\
Yarrow & $11(84.6 \%)$ & $2(15.4 \%)$ & $0(0 \%)$ & $0(0 \%)$ & $2(15.4 \%)$ \\
P-Value & & & & & 0.53
\end{tabular}

*Data are presented as number (percent).

** "Total" refers to the sum of complications from grade 1 to 3 .

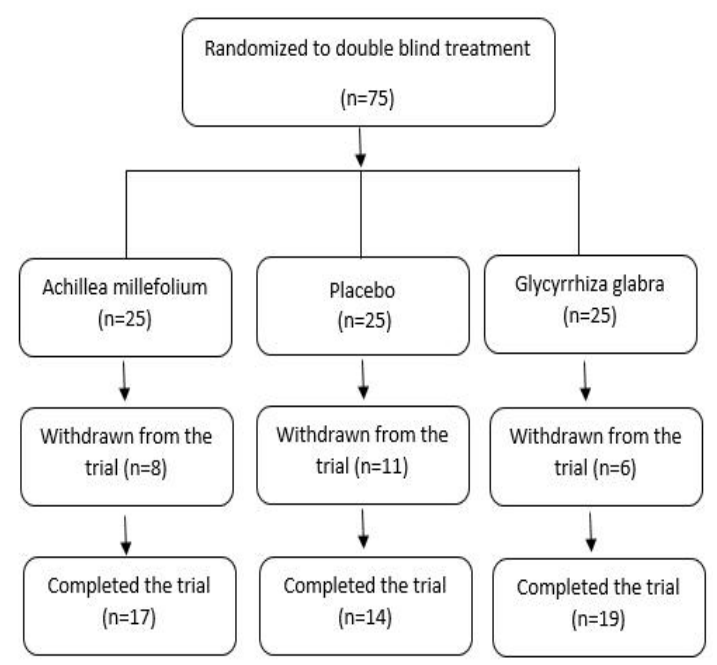

Figure 1. Flowchart Depicting the Study Design.
Table 4. Maximum Grade of Radiation Dermatitis at the End of Treatment

\begin{tabular}{lccccc}
\hline Groups & Grade 0 & Grade 1 & Grade 2 & Grade 3 & Total \\
\hline Licorice & $0(0 \%)$ & $9(64.3 \%)$ & $5(35.7 \%)$ & $0(0 \%)$ & $\begin{array}{c}100 \%) \\
\text { Placebo }\end{array}$ \\
& $1(7.7 \%)$ & $5(38.5 \%)$ & $6(46.2 \%)$ & $1(7.7 \%)$ & $\begin{array}{c}12 \\
(92.3 \%)\end{array}$ \\
Yarrow & $2(14.3 \%)$ & $7(50 \%)$ & $4(28.6 \%)$ & $1(7.1 \%)$ & $\begin{array}{c}12 \\
85.7 \%)\end{array}$ \\
P-Value & & & & & 0.43
\end{tabular}

*Data are presented as number (percent).

** "Total" refers to the sum of complications from grade 1 to 3 .

At the end of the treatment radiation dermatitis occurred in most of the patients. In placebo group, grade 2 toxicities were higher than other two groups; meanwhile, grade 3 toxicities were similar between group 3 and placebo (Table 4). The rate of severe dermatitis (grade 2 and 3) was higher in placebo group, but it was not statistically significant. No case with grade 4 radiation dermatitis was seen in three groups.

\section{Discussion}

Skin toxicity is the most common acute side effect of radiotherapy to the breast that ranges from a mild rash to severe ulceration. Skin reactions to therapeutic radiation depend on the number of radiations, does, site of radiotherapy treatment, and patients specific factors including use of chemical irritants, nutritional status and presence of skin folds [17-20]. Although routine skin care such as keeping the area dry, not robbing the skin and not 
using irritants is important, exclusive use of such handling seems insufficient and prevention of radiation skin damage is a troublesome process for clinicians and patients alike. A wide variety of topical, oral, and intravenous agents have been tested to prevent or to treat radiation-induced skin reactions, but the evidence is insufficient to support the use of a particular agent for this purpose.[7, 8, 21]

Many studies were conducted to find an effective treatment using herbal ingredients to reduce skin reactions, including Aloe-vera, which is widely used to heal burns and wounds [17]. While some studies suggested that Aloe-vera may be useful in preventing radiation induced skin damage, others reported that use of Aloe-vera has no effect or even can worsen dermatitis [22-25].

In the present study, two anti-inflammatory-based herbal drugs were selected based on preclinical activity. The roots of Glycyrrhiza glabra popularly known as Licorice have a variety of biological effects, such as anti-inflammatory, anti-ulcer, antihepatotoxic, antimicrobial, anti-oxidant, cytoprotective, and cytotoxic activities[26-31]. Das et al suggested that Glycyrrhiza glabra can be used effectively in prevention and treatment of oral mucositis post radiation and chemotherapy in patients of cancer, especially of the head and neck region.[14] In another study, it was shown that Licorice root extract could protect plasmid DNA from radiationinduced strand breaks[32]. Moreover, recently Refahi et al demonstrated that administration of Glycyrrhiza glabra extract one hour before thoracic irradiation may be a protective agent against radiation-induced fibrosis in an animal model [11].

Achillea millefolium (Yarrow) is traditionally used in the treatment of gastro-intestinal disorders, healing wounds and providing relief from rashes and itching of various causes. The essential oil of Achillea millefolium was reported to possess strong antioxidant and antimicrobial properties.[9, 33, 34] furthermore, cytotoxic or cytostatic effects of extracts of Achillea millefolium have been demonstrated against various malignant tumor cell lines and flavonols have been identified as responsible for the antitumor activity[35]. To the best of our knowledge this is the first study that has evaluated the possible protective effect of these herbal drugs against radiotherapy induced skin dermatitis.

The results of this study suggest that usage of Achillea millefolium, especially at lower doses of radiation, might decrease radiation induced dermatitis. However, since there were only two cases with grade 1 dermatitis at the end of third week (30 Gy) in this group, more research is required to verify this finding. In the present study, although the severity of skin reactions was lower in two herbal groups, there was not a significant difference between Glycyrrhiza glabra, Achillea millefolium and placebo on preventing radiation dermatitis at the end of treatment.

The main limitation of current study is its small sample size, which render our findings less conclusive. Hence, further study with a larger sample size is required to evaluate the effects of these drugs on radiation skin toxicity in breast cancer patients.

In conclusion the results of this study did not present a significant difference between Glycyrrhiza glabra, Achillea millefolium and placebo on preventing radiation dermatitis. However, the severity of skin reactions was lower in two herbal groups. To better evaluate the effects of these drugs on radiation induced dermatitis in breast cancer patients, a larger sample size is needed.

\section{Conflicts of interest}

The authors declare that they have no conflict of interest.

\section{References}

1. Siegel RL, Miller KD, Jemal A. Cancer statistics, 2015. CA: a cancer journal for clinicians. 2015;65(1):5-29.

2. Group EBCTC. Effects of radiotherapy and of differences in the extent of surgery for early breast cancer on local recurrence and 15-year survival: an overview of the randomised trials. The Lancet. 2006;366(9503):2087-106.

3. Fisher J, Scott C, Stevens R, Marconi B, Champion L, Freedman GM, et al. Randomized phase III study comparing Best Supportive Care to Biafine as a prophylactic agent for radiation-induced skin toxicity for women undergoing breast irradiation: Radiation Therapy Oncology Group (RTOG) 97-13. Int J Radiat Oncol Biol Phys. 2000;48(5):1307-10.

4. Gus'kova AK, Baranov AE, Barabanova AV, Moiseev AA, Piatkin EK. [The diagnosis, clinical picture and treatment of acute radiation sickness in the victims of the Chernobyl Atomic Electric Power Station. II. Non-bone marrow syndromes of radiation lesions and their treatment]. Ter Arkh. 1989;61(8):99-103.

5. Nenot JC. Medical and surgical management for localized radiation injuries. Int J Radiat Biol. 1990;57(4):783-95.

6. D'Haese S, Bate T, Claes S, Boone A, Vanvoorden V, Efficace F. Management of skin reactions during radiotherapy: a study of nursing practice. Eur J Cancer Care (Engl). 2005;14(1):2842.

7. Bolderston A, Lloyd NS, Wong RK, Holden L, RobbBlenderman L, Care SCGGoCCOPiE-B. The prevention and management of acute skin reactions related to radiation therapy: a systematic review and practice guideline. Supportive Care in Cancer. 2006;14(8):802-17.

8. Salvo N, Barnes E, Van Draanen J, Stacey E, Mitera G, Breen $\mathrm{D}$, et al. Prophylaxis and management of acute radiationinduced skin reactions: a systematic review of the literature. Current Oncology. 2010;17(4):94-112.

9. Benedek B, Kopp B. Achillea millefolium L. s.l. revisited: recent findings confirm the traditional use. Wien Med Wochenschr. 2007;157(13-14):312-4.

10. Rackova L, Jancinova V, Petrikova M, Drabikova K, Nosal R, Stefek M, et al. Mechanism of anti-inflammatory action of liquorice extract and glycyrrhizin. Nat Prod Res. 2007;21(14):1234-41.

11. Refahi S, Minaei B, Haddadi GH, Khoei S, Bakhtiarian A, Pourissa M, et al. Histopathological Evaluation of the Effectiveness of Glycyrrhizic Acid as a Radioprotector Against the Development of Radiation-Induced Lung Fibrosis. Iran J Radiol. 2016;13(2):e21012.

12. ROSSI T, BENASSI L, MAGNONI C, RUBERTO AI, COPPI A, BAGGIO G. Effects of glycyrrhizin on UVBirradiated melanoma cells. in vivo. 2005;19(1):319-22.

13. Gandhi NM, Maurya DK, Salvi V, Kapoor S, Mukherjee 
T, Nair CKK. Radioprotection of DNA by glycyrrhizic acid through scavenging free radicals. Journal of radiation research. 2004;45(3):461-8.

14. Das D, Agarwal S, Chandola H. Protective effect of Yashtimadhu (Glycyrrhiza glabra) against side effects of radiation/chemotherapy in head and neck malignancies. AYU (An international quarterly journal of research in Ayurveda). 2011;32(2):196.

15. Nakagawa H. Comparison of the efficacy and safety of $0.1 \%$ tacrolimus ointment with topical corticosteroids in adult patients with atopic dermatitis: review of randomised, double-blind clinical studies conducted in Japan. Clin Drug Investig. 2006;26(5):235-46.

16. Nemeth E, Bernath J. Biological activities of yarrow species (Achillea spp.). Curr Pharm Des. 2008;14(29):3151-67.

17. Barkham AM. Radiotherapy skin reactions and treatments. Prof Nurse. 1993;8(11):732-6.

18. Hopewell JW. The skin: its structure and response to ionizing radiation. Int J Radiat Biol. 1990;57(4):751-73.

19. Maddocks-Jennings W, Wilkinson JM, Shillington D. Novel approaches to radiotherapy-induced skin reactions: a literature review. Complement Ther Clin Pract. 2005;11(4):224-31.

20. Sitton E. Early and late radiation-induced skin alterations. Part II: Nursing care of irradiated skin. Oncol Nurs Forum. 1992;19(6):907-12.

21. Chan RJ, Webster J, Chung B, Marquart L, Ahmed M, Garantziotis S. Prevention and treatment of acute radiationinduced skin reactions: a systematic review and metaanalysis of randomized controlled trials. BMC cancer. 2014;14(1): 1

22. Olsen DL, Raub W, Jr., Bradley C, Johnson M, Macias JL, Love V, et al. The effect of aloe vera gel/mild soap versus mild soap alone in preventing skin reactions in patients undergoing radiation therapy. Oncol Nurs Forum. 2001;28(3):543-7.

23. Williams MS, Burk M, Loprinzi CL, Hill M, Schomberg PJ, Nearhood K, et al. Phase III double-blind evaluation of an aloe vera gel as a prophylactic agent for radiation-induced skin toxicity. Int J Radiat Oncol Biol Phys. 1996;36(2):345-9.

24. Haddad P, Amouzgar-Hashemi F, Samsami S, Chinichian S, Oghabian M. Aloe vera for prevention of radiation-induced dermatitis: a self-controlled clinical trial. Current Oncology. 2013;20(4):e345.

25. Su CK, Mehta V, Ravikumar L, Shah R, Pinto H, Halpern $\mathrm{J}$, et al. Phase II double-blind randomized study comparing oral aloe vera versus placebo to prevent radiation-related mucositis in patients with head-and-neck neoplasms. International Journal of Radiation Oncology* Biology* Physics. 2004;60(1):171-7.

26. Aly AM, Al-Alousi L, Salem HA. Licorice: a possible antiinflammatory and anti-ulcer drug. AAPS PharmSciTech. 2005;6(1):E74-E82.

27. Mitscher LA, Park YH, Clark D, Beal JL. Antimicrobial agents from higher plants. Antimicrobial isoflavanoids and related substances from Glycyrrhiza glabra L. var. typica. Journal of natural products. 1980;43(2):259-69.

28. Vaya J, Belinky PA, Aviram M. Antioxidant constituents from licorice roots: isolation, structure elucidation and antioxidative capacity toward LDL oxidation. Free Radical Biology and Medicine. 1997;23(2):302-13.

29. Kim SC, Byun SH, Yang CH, Kim CY, Kim JW, Kim SG. Cytoprotective effects of Glycyrrhizae radix extract and its active component liquiritigenin against cadmium-induced toxicity (effects on bad translocation and cytochrome c-mediated PARP cleavage). Toxicology. 2004;197(3):239-

\section{1.}

30. Jo E-H, Kim S-H, Ra J-C, Kim S-R, Cho S-D, Jung J-W, et al. Chemopreventive properties of the ethanol extract of chinese licorice (Glycyrrhiza uralensis) root: induction of apoptosis and G1 cell cycle arrest in MCF-7 human breast cancer cells. Cancer letters. 2005;230(2):239-47.

31. Rossi T, Castelli M, Zandomeneghi G, Ruberto A, Benassi L, Magnoni C, et al. Selectivity of action of glycyrrhizin derivatives on the growth of MCF-7 and HEP-2 cells. Anticancer research. 2002;23(5A):3813-8.

32. Shetty T, Satav J, Nair C. Protection of DNA and microsomal membranes in vitro by Glycyrrhiza glabra L. against gamma irradiation. Phytotherapy Research. 2002;16(6):576-8.

33. Candan F, Unlu M, Tepe B, Daferera D, Polissiou M, Sökmen A, et al. Antioxidant and antimicrobial activity of the essential oil and methanol extracts of Achillea millefolium subsp. millefolium Afan.(Asteraceae). journal of ethnopharmacology. 2003;87(2):215-20.

34. Shahbazi Y, Zadeh MS. In vitro assessment of antimicrobial efficacy of alcoholic extract of Achillea millefolium in comparison with penicillin derivatives. J Anim Vet Adv. 2008;7(4):508-11.

35. Csupor $\square$ Löffler B, Hajdú Z, Zupkó I, Réthy B, Falkay G, Forgo P, et al. Antiproliferative effect of flavonoids and sesquiterpenoids from Achillea millefolium sl on cultured human tumour cell lines. Phytotherapy Research. 2009;23(5):672-6.

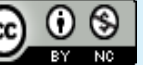

This work is licensed under a Creative Commons AttributionNon Commercial 4.0 International License. 